\title{
Gastrointestinal Stromal Tumor in Sigmoid Colon at a Tertiary Care Hospital: A Case Report
}

\author{
Saha $\mathrm{PK}^{1}$, Roy $\mathrm{R}^{2}$, Saha $\mathrm{H}^{3}$, Rahman $\mathrm{MM}^{4}$, Haq $\mathrm{MM}^{5}$, Bulbul $\mathrm{S}^{6}$
}

\begin{abstract}
Gastrointestinal stromal tumors (GISTs) are the mesenchymal tumors representing the most common mesenchymal neoplasm of gastrointestinal tract. However, GIST is recognized tumor entity and the literature on these stromal tumors has rapidly expanded. This present case report has been found in Dhaka at a tertiary care hospital in a male patient. The patient was operated at the local area before admitted at this hospital where he was misdiagnosed. In this hospital the diagnosis was confirmed by histopathologically. Surgical resection was performed laparoscopically by a skilled surgical team. [J Shaheed Suhrawardy Med Coll, 2013;5(1):59-62]
\end{abstract}

Keywords: Gastrointestinal stromal tumor, GIST, sigmoid colon

Received: December 2012; Revised: March 2013; Accepted: May 2013

\section{Introduction}

Gastrointestinal stromal tumors (GISTs) are a subset of mesenchymal tumors ${ }^{1}$. It has been established that GISTs arise from multi-potential mesenchymal stem cells ${ }^{2}$. This accounts for less than $1.0 \%$ of all gastrointestinal tract tumors ${ }^{3}$.

The incidence of GIST is approximately 10-20/million people/year ${ }^{1}$. More than $90.0 \%$ of GISTs occur in adults over 40 years old though it has been reported in all ages, including children ${ }^{4}$. The most common location of GIST is stomach (50.0-60.0\%) and small intestine (30.0\%-40.0\%); however, five to ten percent of GISTs arise from the colon and rectum, and $5.0 \%$ are located in the esophagus ${ }^{1}$. The clinical features of GIST are variable. Additionally, only $70.0 \%$ of the patients are symptomatic, while $20.0 \%$ are asymptomatic and $10^{\circ} \%$ are detected at autopsy ${ }^{5}$. The clinical signs and symptoms are related to the presence of a mass or bleeding ${ }^{6}$. However, $10.0 \%$ remain asymptomatic due to small size $(<2 \mathrm{~cm})$ which are diagnosed incidentally ${ }^{7}$. Bleeding comprises the most common symptom and it is attributed to the erosion of the gastrointestinal tract lumen. Bleeding occurring into the abdominal cavity leads to acute abdominal pain that usually ends up in emergency surgery ${ }^{1}$. Common finding is the abdominal mass and produces the symptoms according to the location of GIST like dysphagia in the esophagus, biliary obstruction around the ampula of Vater or even intrussusception, in the small bowel. This present case report has been found in the tertiary care hospital in Dhaka.

\section{Case Presentation}

A 40 years old male patient was admitted in the Department of Surgery at Shaheed Suhrawardy Medical College \& Hospital, Dhaka. He was normotensive, non diabetic, as well as non-asthmatic working as weaver hailing from north-west of Dhaka. He was admitted with the complaints of left lower abdominal lump for 3 months. The lump was gradually increasing in size and associated with occasional mild pain. The pain was dull aching in nature without any radiation of pain or presence of vomiting which was relieved by taking medications. Per rectal bleeding, mucous discharge, sense of incomplete evacuation, cough, haemoptysis, jaundice, weight loss or fever were absent. But the patient had a history of gradually increasing lower abdominal lump with pain in 2

1. Dr. Pankaj Kumar Saha, Senior Consultant, Department of Surgery, Shaheed Suhrawardy Medical College \& Hospital, Dhaka

2. Dr. Ratna Roy, Assistant Professor, Department of Anatomy, Dr. Serajul Islam Medical College \& Hospital, Dhaka

3. Dr. Haridas Saha, Resident Surgeon, Department of Casualty, Shaheed Suhrawardy Medical College \& Hospital, Dhaka

4. Dr. Md. Mamunur Rahman, Resident Surgeon, Department of Casualty, Shaheed Suhrawardy Medical College \& Hospital, Dhaka

5. Dr. Mohammad Mahmudul Haq, Medical Officer, Department of Surgery, Shaheed Suhrawardy Medical College \& Hospital, Dhaka

6. Dr. Surayea Bulbul, Junior Consultant, Department of Obstetrics \& Gynaecology, Shaheed Suhrawardy Medical College \& Hospital, Dhaka

\section{Correspondence}

Dr. P. K. Saha, Senior Consultant, Department of Surgery, Shaheed Suhrawardy Medical College \& Hospital, Sher-E-Bangla Nagar, Dhaka-1207, Bangladesh; Email: pksaha2@yahoo.com; Cell No.: +8801711153692 
years back and was underwent an operation 10 months back at the local area. On examination, the physique of the patient and the nutritional status were normal with no pal pable accessible peripheral lymph nodes. On inspection of abdomen, a lower midline scar mark was found with no visible lump or peristalsis. On palpation, a non-tender, intra-abdominal lump was found in left illiac fossa with part of hypogastrium which was ovoid in shape measuring about $8 \mathrm{~cm}$ by $10 \mathrm{~cm}$ The surface was smooth with firm in consistency. Margin was ill defined which was moved in all directions. There is no ascites or organomegaly. Other systemic examination reveals normal finding. The reports of different investigations were showed that haemoglobin was normal level $(12.9 \mathrm{gm} / \mathrm{dl})$ with normal ESR $(15 \mathrm{~mm}$ in 1st hour). The total count of WBC was slightly raised $(10,000 / \mathrm{cmm})$ with neutrophilia (70\%) with monocytosis (7\%). The normal levels of random blood sugar (78 mg/ $\mathrm{dl})$, serum creatinine $(0.9 \mathrm{mg} / \mathrm{dll})$, routine examination of urine were reported as well. No abnormalities were detected in chest X-ray or ECG. Liver function test were normal (Serum Bilirubin $0.8 \mathrm{mg} / \mathrm{dl}$ and SGPT $27 \mathrm{U} / \mathrm{L}$ ). Monteux Test was negative $(7 \mathrm{~mm})$. The tumor marker CEA (5.25 ng/ml) level was slightly raised. The ultrasonography of whole abdomen report showed that a lobulated mass lesion measuring about $(12.7 \times 8.8) \mathrm{cm}$ is seen in left lumber $\&$ left side of pelvic cavity suggestive of gut related mass which may be GIST or Lymphoma with intra abdominal lymphadenopathy.

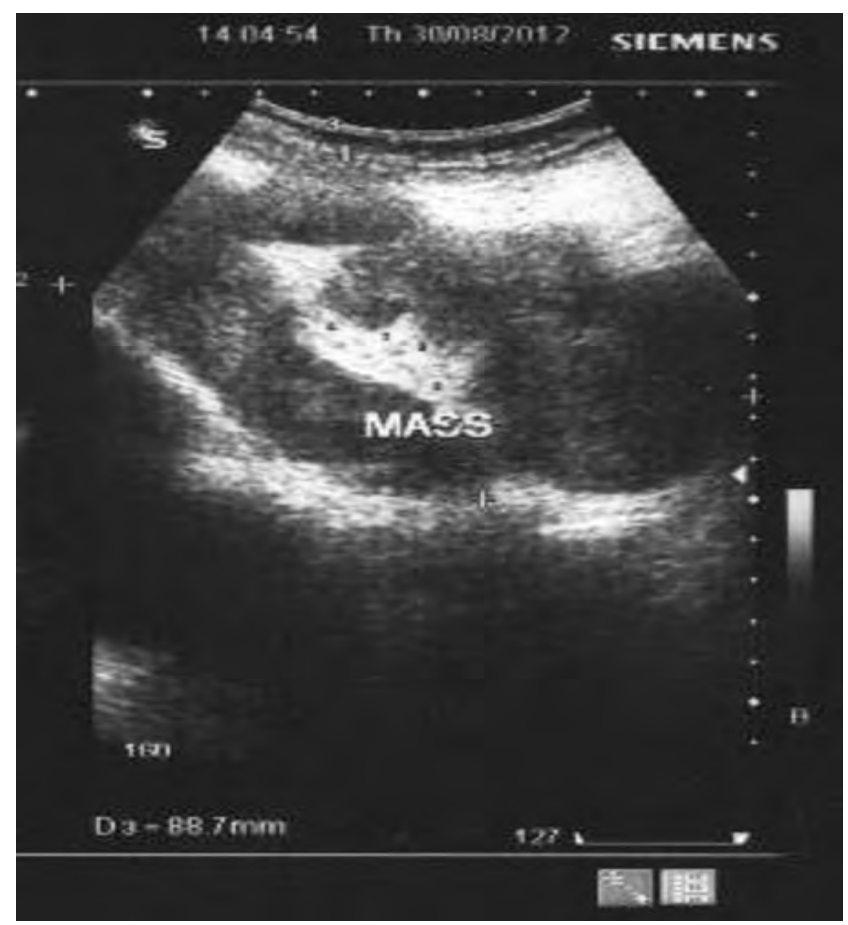

Figure I: USG of abdomen showing intra-abdominal mass

Axial CT scan of whole abdomen with pre and postcontrast showed multiple sub centimeter $(<\mathrm{lcm})$ nonenhancing areas noted along the mesentery in pelvic cavity. No ascites or pleural effusion could be seen. Prostate gland was mildly enlarged $(4.7 \mathrm{~cm} \times 3.2 \mathrm{~cm})$.

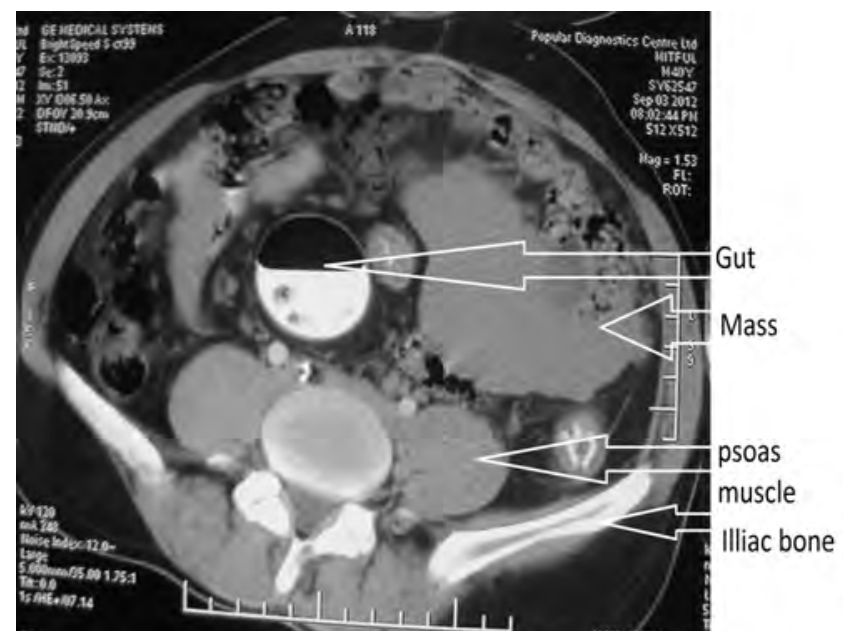

Figure II: CT scan of abdomen showing intra-abdominal mass (Sagittal plan)

Irregular thick walled bowel related mass was noted in right and left side of pelvic cavity which showed heterogeneous enhancement after contrast. No intra Iuminal contrast was visualized. Thus giving the impression of bowel related mass which may be intestinal tuberculosis or Iymphoma or GIST with mesenteric Iymphadenopathy. Core biopsy was performed and showed fibro-fatty tissue containing a few chronic inflammatory cells without any gastrointestinal stromal tumor. No malignancy was found as well. Colonoscopy showed normal colon upto hepatic flexure as well as the rectum and anal canal. After counseling patient was prepared laparoscopy followed by laparotomy after bowel was prepared by enema simplex. During per operative findings, there is a lobulated mass, measuring about $15 \times 12 \mathrm{~cm}$ arising from wall of sigmoid colon and bleeds on touch. There is no ascites, no peritoneal seeding and liver is normal. Histopathology examination was performed and was shown a tumor made of spindle shaped stromal cells. The tumor cells are arranged in interlacing pattern. Overlying mucosa is not found with mitotic figures in 550/HPF. Tumor necrosis vascular invasion, Iymphatic invasion, resection margin and perineural invasion were not found. The diagnosis was confirmed as gastrointestinal stromal tumor in sigmoid colon (GIST) in intermediate risk category. The definitive treatment was given by resection and anastomosis of sigmoid colon. The patient was advised to do follow up CT scan of abdomen 4 monthly for 3 years, 6 monthly for upto 5 years and yearly for life long.

\section{Discussion}

Gastrointestinal stromal tumors (GISTs) represent the most common mesenchymal neoplasms of gastrointestinal tract ${ }^{1}$. However, the precise incidence of GIST is unknown because of the incomplete definition and classification? Over $90.0 \%$ of GISTs occur in adults over 40 years old with a median age of 63 years ${ }^{1}$. In this case report the age 
was similar with the previous study. However, GIST cases have been reported in all ages, including children. The incidence between the sexes is the same, al though a study reported that there is a slight predominance of malest. The case report shows that the patient was male which is consistent with the present study. The reason is not explained. However, there are no elements that indicate any association with geographic location, ethnicity, or occupation. Though the commonest site of GIST is stomach (50.0-60.0\%) and small intestine (30.0\%-40.0\%), 5.0 to $10.0 \%$ of GISTs arise from the colon and rectum ${ }^{1}$. In this case report the site of origin of the GIST is from the colon and this gives an impression that GIST can occur from also from colon. However, there have been reported rare cases in the gallbladder, pancreas, liver and urinary bladder. In cases, where GIST occurs outside the GI tract, the tumors are known as extra-gastrointestinal stromal tumors (EGISTs) ${ }^{8}$.

GISTs show a variety of differentiation spectrum, ranging from fully differentiated tumors with myoid, neural or ganglionic plexus phenotype to those with incomplete or mixed differentiation'. However, it has become clear from immunohistochemistry test that the GIST cells are closely related to the multi-potential mesenchymal stem cells which were not performed in the present case report. GISTs have many different histological features ${ }^{1}$. In this present case report histopathology examination was showed a tumor made of spindle shaped stromal cells arranged in interlacing pattern. Additionally, GISTs are usually smooth gray and white tumors which are well circumscribed, usually with a pseudo-capsule which is consistent with the present case report. Less frequently, a small area of hemorrhage, cystic degeneration and necrosis may be visible ${ }^{9}$ though tumor necrosis, vascular invasion, Iymphatic invasion, resection margin and perineural invasion are absent in the present case report Generally, GIST varies greatly in size from a few millimeters to $>30$ $\mathrm{cm}$, the median size though is between $5 \mathrm{~cm}$ and $8 \mathrm{~cm}^{1}$.

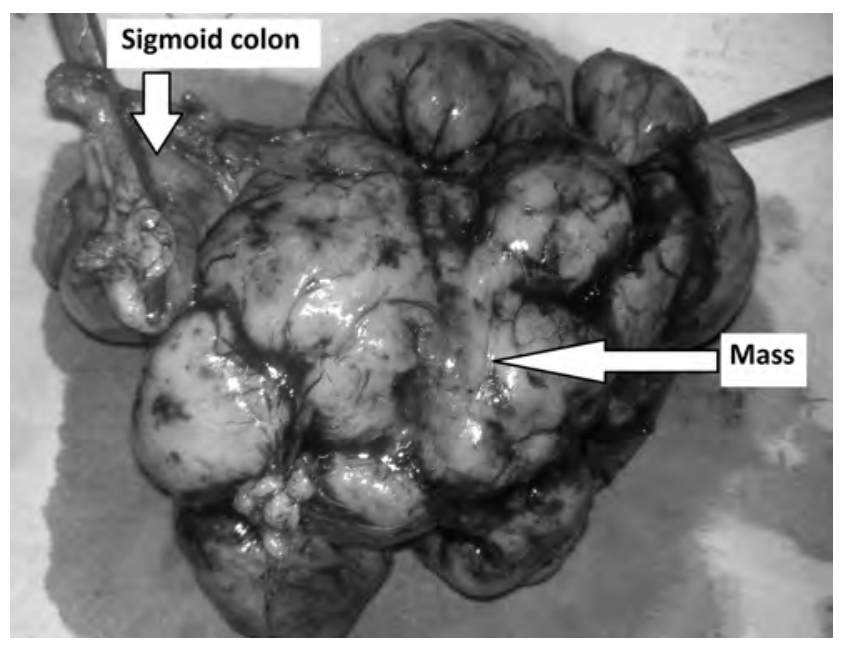

Figure III: Showing the resected mass with part of sigmoid colon
The CT scan report showed the size of the tumor of this patient $(1 \mathrm{~cm})$ which is very similar to the others findings. Macroscopically, GIST usually has an exophytic growth and as a result, the intra-operative appearance commonly resembles of a mass that is attached to the stomach, projecting into the abdominal cavity and displacing all the other organs ${ }^{10}$. Usually mucosal ulceration is present in $50 \%$ cases though it is absent in the present case report

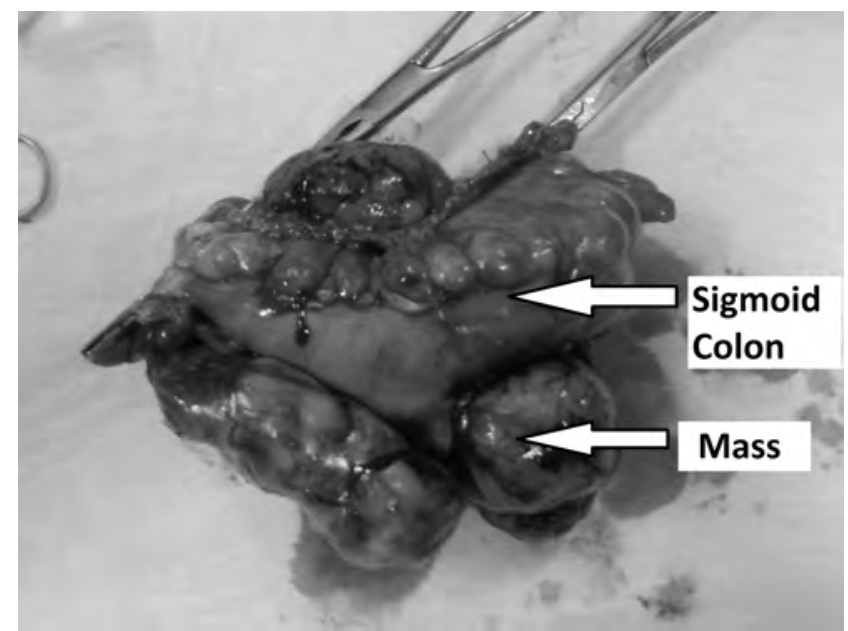

Figure IV: Showing the resected mass with part of sigmoid colon

Diagnosis of GIST is often delayed, due to the vague nature of symptoms, for even 6 months after the onset of the symptoms ${ }^{11}$. In this present case report surgical operation was performed in the local area with very limited resources to make it confirmed. In addition to that the present case report patient was poor who was wandering different places to get the proper treatment. Due to these reason the diagnosis was delayed in this patient. Although, the diagnostic procedure includes several examinations, like barium examination of the Gl tract, computer tomography and angiography, none of them can establish the diagnosis ${ }^{1}$. This is consistent with the present case report. The preoperative percutaneous biopsy should not be used because it is associated with a significant risk of tumor rupture or dissemination ${ }^{12}$. The significance of endoscopic ultra-sound guided fine needle aspiration has been pointed out in several studies ${ }^{13}$ and the reported accuracy is $80.0^{\circ} \%-85.0^{\circ} \%$. However the present case report section from core biopy has shown fibrofatty tissue containing a few chronic inflammatory cells with no gastrointestinal stromal tumor or malignancy which is inconsistent with other findings ${ }^{11,12}$.

Regarding the management of GIST, surgical resection of the local disease is the gold standard therapy ${ }^{1}$. During operation the goal is to complete resection of the disease with avoidance of tumor rupture ${ }^{14}$. In the present case report surgical resection was performed by laparoscopically. The aim of the laparoscopic surgery is the same, aiming at the complete removal of thetumor, 
avoiding tumor rupture, as peritoneal seeding affects disease free period ${ }^{15,16}$. It is very important that the tumor size determines the survival and not the negative microscopic surgical margins ${ }^{17}$. Regional lymph node resection has no value since GIST rarely gives rise to lymph node metastases which was not performed in the present case report GISTs are soft and fragile, so a tumor rupture must be avoided because it is associated with an increased risk for development of peritoneal implants rupture ${ }^{14}$. For this reason laparoscpically removal is very much important which has been followed in the present case report. However, there is also evidence that laparoscopic approach for the resection of tumour is effective, with minimal morbidity and no reported mortality ${ }^{18}$. It is very important that during laparoscopic resection, several factors including patient characteristics, tumor size, location, invasion as well as the surgeon's experience need to be taken under consideration ${ }^{19,20}$. As it is al ready mentioned, surgery is the preferred management of GISTs, where feasible, complete surgical resection is connected with $48-65 \%$ five year survival ${ }^{21}$. Partial resection must only be performed in case of large tumors, for palliative purposes or the control of symptoms or complications, such as compression of other organs, hemorrhage or even pain ${ }^{18}$.

\section{Conclusion}

GISTs is not uncommon in Bangladesh. Proper evaluation of the tumor should be carried out to give the appropriate treatment without seeding due to rupture of the tumor during operation. To avoid this condition laparoscopically removal of GISTs has been recommended with skilled hand surgeons which gives minimal invasion and maximum better outcome.

\section{References}

1. Stamatakos M, Douzinas E, Stefanaki C, Safioleas P, Polyzou E, Levidou G, et al. Gastrointestinal stromal tumor. World J Surg Oncol 2009;7(5):61-5

2. Joensuu H: Gastrointestinal stromal tumor (GIST). Annals Oncology 2006, 17(10):280-286

3. Agaram NP, Besmer P, Wong CC, Guo Tianhua, Socci ND, Maki RG, et al.Pathologic and Molecular Heterogeneity in Imatinib-Stable or Imatinib-Responsive Gastrointestinal Stromal Tumors. Clin Cancer Res 2007;13(1):170-181

4. Kim KM, Kang DW, Moon WS, Park JB, Park CK, Sohn JH, et al. Gastrointestinal Stromal Tumor Committee; The Korean Gastrointestinal Pathology Study Group. Gastrointestinal Stromal Tumors in Koreans: Incidence and the Clinical, Pathologic and Immunohistochemical Findings. J Korean Med Sci 2005;20:977-984

5. Heinrich MC, Corless CL, Duensing A, McGreevey L, Chen CJ, J oseph N, et al. PDGFRA activating mutations in gastrointestinal stromal tumors. Science 2003;299:708-710

6. Fletcher CD, Berman JJ, Corless C, Gorstein F, Lasota J, Longley BJ, et al. Diagnosis of gastrointestinal stromal tumors: A consensus approach.
Hum Pathol 2002;33:459-465

7. Nilsson BP, Bumming $P$, Meis-Kindblom JM, Odén $A$, Dortok $A$, Gustavsson B, et al. Gastrointestinal stromal tumors: The incidence, prevalence, clinical course, and prognostication in the preimatinib mesylate era. Cancer 2005;103:821-829

8. Miettinen M, Lasota J. Gastrointestinal stromal tumors - definition, clinical, histological, immunohistochemical, and molecular genetic features and differential diagnosis. Virchows Archiv 2001;438:1-12

9. Akahoshi K, Sumida Y, Matsui N, Masafumi O, Akinaga R, Kubokawa $M$, et al. Preoperative diagnosis of gastrointestinal stromal tumor by endoscopic ultrasound-guided fine needle aspiration. World J Gastroenterol 2007;13(14):2077-2082

10. Rubin BP, Antonescu CR, Scott-Browne JP, Comstock ML, Gu Y, Tanas MR, et al. A knock-in mouse model of gastrointestinal stromal tumor harboring kit K641E. Cancer Res 2005;65:6631-39

11. Tran T, Davila JA, El-Serag HB. The epidemiology of malignant gastrointestinal stromal tumors: an analysis of 1458 cases from 1992 to 2000. AmJ Gastroenterol 2005;100:162-168

12. Jamali F, Darwiche S, El-Kinge N, Tawil A, Sowed A. Disease progression following Imatinib failure in gastrointestinal stromal tumors: Role of surgical therapy. Ongologist 2007;12:438-442

13. DeMatteo RP, Lewis JJ, Leung D, Mudan SS, Woodruff J M, Brennan MF. Two hundred gastrointestinal stromal tumors: Recurrence patterns and prognostic factors for survival. Ann Surg 2000;231:51-58

14. Verweij J, Casali PG, Zalcberg J, LeCesneA, Reichardt P, Blay JY, et al. Progression-free survival in gastrointestinal stromal tumours with high-dose imatinib: randomized trial. Lancet 2004;364:1127-1134

15. Zalcberg JR, Verweij J, Casali PG, Le CesneA, Reichardt P, Blay JY, et al. EORTC Soft Tissue and Bone Sarcoma Group, the Italian Sarcoma Group; Australasian Gastrointestinal Trials Group. Outcome of patients with advanced gastrointestinal stromal tumors (GIST) crossing over to a daily imatinib dose of $800 \mathrm{mg}$ after progression on $400 \mathrm{mg}$ - an international, intergroup study of the EORTC, ISG and AGITG. ProcAm Soc Clin Oncol 2004; 23:815-20

16. Demetri GD, vanOosterom AT, Blackstein $M$, Shah $M H$, Verweij J, McArthur G, et al. Phase 3, multicenter, randomized, double-blind, placebo-controlled trial of SU11248 in patients following failure of imatinib for metastatic GIST. ProcAm Soc Clin Oncol 2005;23:308-12

17. Rankin $C$, Von Mehren $M$, Blanke $C$. Dose effect of imatinib in patients with metastatic GIST - Phase III Sarcoma Group Study 50033. ProcAm Soc Clin Oncol 2004;23:815-21

18. Blay JY, Bonval ot S, Casali P, Choi H, Debiec-Richter M, DeiTos AP, et al. GIST consensus meeting panelists. Consensus meeting for the management of gastrointestinal stromal tumors. Report of the GIST Consensus Conference of 20-21 March 2004, under the auspices of ESMO. Ann Oncol 2005;16:566-78

19. Tamborini E, Bonadiman L, Greco A, Albertini V, Negri T, Gronchi A, et al. A new mutation in the KIT ATP pocket causes acquired resistance to imatinib in a gastrointestinal stromal tumor patient. Gastroenterology 2004; 127:294-299

20. Li FP, Fletcher JA, Heinrich MC, Garber JE, Sallan SE, CurielLewandrowski $C$, et al. Familial gastrointestinal stromal tumor syndrome: phenotypic and molecular features in a kindred. J Clin Oncol 2005;23:2735-43

21. Parfitt J, Streutker C, Riddell R, Driman D. Gastrointestinal stromal tumors: A contemporary review. Pathology - Research and Practice 2006;202:837-47 